\title{
28 COLLABORATIVE E-ENGINEERING ENVIRONMENTS TO SUPPORT INTEGRATED PRODUCT DEVELOPMENT
}

\author{
Ricardo Mejia ${ }^{1}$, Joaquín Aca ${ }^{1}$, Horacio Ahuett ${ }^{2}$, Arturo Molina ${ }^{1}$, \\ ${ }^{\prime}$ Centro de Sistemas integrados de Manufactura - ITESM \\ ${ }^{2}$ Centro de Diseño e innovación de productos-ITESM \\ Ave. Eugenio Garza Sada 2501 Sur \\ Monterrey, N.L. 64849 MEXICO \\ (52-81) 8158-2032/86, fax: (52-81) 8328-4123 \\ rimejia@itesm.mx,aca@itesm.mx, \\ horacio.ahuett@itesm.mx,armolina@itesm.mx
}

\begin{abstract}
Nowadays global product development tasks are executed by different facilities usually at different geographically location, where design and manufacturing teams must work remotely. This situation requires three major issues to be tackled: (1) implementation of a collaborative Integrated Product Development process among the different companies participating in the Product Life Cycle activities; (2) establishment of environments that foster the coordination and cooperation among engineering groups; (3) integration of software tools that allows the exchange of information and knowledge among engineers in an effective and efficient manner. A reference model for integrated product, process and manufacturing systems development is described and a methodology to implement Collaborative e-Engineering Environments is proposed to provide a model to transfer the e-engineering concepts to the industry. A case study is described that applied the proposed methodologies to set-up a collaborative environment for high tech product development using low-cost technologies.
\end{abstract}

\section{INTRODUCTION}

Global companies have been forced to define and standardize their product development and manufacturing processes, in order to coordinate at a global level all their activities related to an "Integrated Global Product Development". This concept means the integration of all the activities, methods, information and technologies to conceive the complete Product Life Cycle [Tipnis 1999]. At the same time the globalization of the industrial activities and decentralization of many manufacturing processes leads companies to work in relation to very distant collaborators. Due to these trends, organizations are constantly seeking better methods for improving productivity and effectiveness in the accomplishment of engineering tasks, primarily through the use of information technology. Examples include the need to reduce the cost of designing new products and to significantly shrink overall development life cycles [Bochenek and Ragusa 2001]. For these reasons the creation of collaborative e-Engineering environments has been a key challenge in information technology. 
Information technology must be designed, implemented and integrated to enable people to collaborate and coordinate their design and manufacturing activities. But technology is not enough; a well defined development process where activities, information/knowledge, techniques and partners involved has to be modeled and visualized in order to have a reference for the global development process. Integrated Product and Process Development (IPPD) is a management technique that simultaneously integrates all essential acquisition activities through the use of multidisciplinary teams to optimize the design, manufacturing, and supportability processes [OUSD 1998]. There are methodologies to support the implementation of IPPD concepts, among them, [Lee et. al. 2003], [Mervyn et. al. 2003], [Song et. al. 2001], [Swink et. al. 1996] and [Yan and Zhou 2003]. However important considerations are: (a) integration level of methods and tools proposed is restricted to specific development activities and (b) the absence of one methodology able to integrate complete product life cycle.

This paper describes a methodology that has been used to design, integrate and execute collaborative e-Engineering environments based on the concept of IPPD. Two case of study related to the application of the reference model is presented to demonstrate its applicability in real situations.

\section{DESIGNING AND CONFIGURING COLLABORATIVE e- ENGINEERING ENVIRONMENTS}

A process development model is the basis to design, configure and implement the collaborative e-Engineering Environment. Figure 1 depicts the methodology used:

\section{I) Determine the Company process Requirements}

Identify the company requirements for product, process and/or manufacturing system development. Once the process has been defined, an AS-IS process model is built. This model should include information regarding the activities, information/knowledge, human and technological resources and organizational issues (practices, procedures, responsibilities). Sometimes for new processes implementation, an AS-IS model might not exists, therefore the methodology begin with the creation of a TO-BE model.

\section{II) Assessment and model TO-BE of the development process}

The AS-IS model represents how a process is currently executed. An assessment is carried out based on four views: process, information/knowledge, organization and resources. Afterwards, the TO-BE process is modeled, including all the proposed modification to have a more efficient/effective model. This TO-BE process model will be used to define a Workflow in further stages.

\section{III) Design and integration of environment and applications}

Four main steps must be undertaken in order to integrate collaborative engineering environments: 
- Modeling the workflow (MODEL): Workflow modeling allows the analysis and visualization of the whole development process. The workflow logic is defined using a Workflow Management System (WFMS) to describe all the elements of the process. It is important to mention that the key elements to describe in a workflow are: activities, flow of information, people, and decisions.

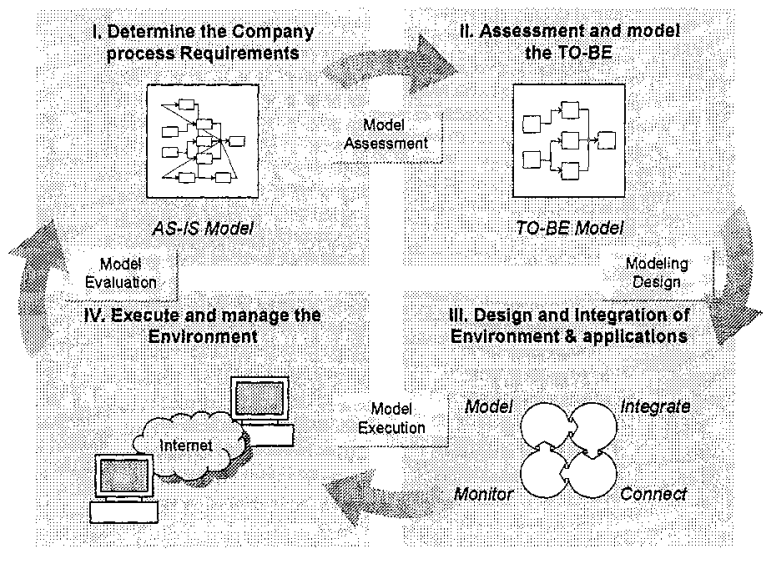

Figure 1 - Methodology for designing and configuring Collaborative e-Engineering Environments

- Selection and Integration of e-Engineering applications (INTEGRATE): The different applications required in a collaborative environment includes: 1) Functional: function oriented systems that support engineers in specific tasks, for example CAD, CAM, CAE, KBES, and Rapid Prototyping tools; 2) Coordination: coordination systems to support sequencing of activities and flow of information., for example workflow and project management; 3) Collaboration: collaboration systems to foster cooperation among engineer, i.e. CSCW - Computer Supported Cooperative Working; and 4) Information Management: product and manufacturing information management systems, knowledge based management systems. The combination of application will be aligned to the company specific needs.

- Connect external applications using standards and web protocols (CONNECT): in a collaborative engineering environment there is a need to connect external applications that customers or suppliers are using. Therefore the required communication standards and web protocols must be defined. Some of the applications includes: marketing information exchange (e.g. Web pages, ecatalogues), Manufacturing / Production systems (e.g. e-RFQ, ERP, MES Manufacturing Execution Systems), and other CAD/CAM/CAE systems.

- Definition of performance measures and monitoring techniques (MONITOR): the decision of "what" to monitor in the process is established. Performance measure could include: time, costs and resources usage. This is important to allow managers to coordinate, track and control the process at the execution 
phase. If the WFMS allows the application of business process intelligent tools depth analysis of process behavior and performance can be carried out.

\section{IV) Execute and manage the Workflow}

The workflow is executed once all the stages from the collaborative engineering configuration methodology are covered. The execution of a Collaborative Environment based on a WFMS allows process analysis that can be carried out in order to improve the process. The process management tracks events and data from the Workflow environment execution. It provides both real-time and historical tracking of what is occurring in the workflow engine. All these information can help to improve the process. Based on the analysis and suggested modification a new potential TO-BE model (the currently process in execution is the AS-IS process) and maybe new design improvements can be proposed to improve the business process.

\section{A PILOT PROJECT FOR COLLABORATIVE HIGH TECH PRODUCT DEVELOPMENT}

The Northern Mexican Region has been seen the establishment of a large number of US manufacturing facilities looking for advantages in Mexican manufacturing expertise and close to border localization. The tasks of design and manufacturing of products are being executed by different facilities of large corporation usually at different geographically locations. Problems faced between US and Mexican companies are (a) lack of collaboration during early stages of life cycle product development; and (b) deficient knowledge of manufacturing process capabilities. To demonstrate how the collaborative product development can be attained an Engineering Collaboration E nvironment for $\mathrm{H}$ igh $\mathrm{T}$ ech $\mathrm{P}$ roducts $\mathrm{p}$ ilot p roject was developed.

A methodology was configured to develop High-Tech Products (Mechatronic products) between US and Mexican companies. The product to develop was a communication device for children with special needs for communication. The target was to complete a functional prototype in six months. The responsibilities and resources to ensure the project execution were delegate to students at ITESM. Students from Electronic Department of ITESM were responsible to design the Printed Circuit Board (PCB) of the device and students from Mechanical Engineering Department were responsible to design and fabricate the prototypes of the Housing and fabricate the prototype of the PCB in the Manufacturing Research Center facilities at ITESM.

Step $I$ and Step $I I$ were undertaken during the configuration of a new process for High-Tech products development. For this reason the proposed development process is directly a TO-BE model. A detail description of the process model was created specifying specific activities, methods, tools and people.

For Step III) a selection of freeware tools was a priority. The purpose of this exercise was to explore a broader range of collaboration tools, because past experiences in designing and implementing Collaboration Environments (Web portals and Groupware) had shown that collaboration tools already integrated in those systems were limited [Aca et al. 2003]. As a consequence, several tools were 
tested, and it was concluded that commercial public domain tools will be used. The following applications were evaluated: $\mathrm{MSN}^{\mathrm{TM}}$, Yahoo ${ }^{\mathrm{TM}}$, and NetMeeting ${ }^{\mathrm{TM}}$. All of these applications provide a high variety of collaboration tools. For this specific pilot project, the MSN applications were selected to demonstrate the concepts. Then, the following aspects were considered to design an environment with free-ware tools:

MODEL: In this pilot project, it was necessary to create a shared space, using MSN groups, to be used as an integrated platform (environment). However in this kind of environments, there is a lack of workflow tools. Therefore the flow of activities and the methods and tools required for each activity, were implemented using a set of working spaces were each phase of the development process included all the workflow components.

INTEGRATE: Functional: the engineering stand-alone applications used were: Mechanical Desktop, Design explorer and Electronic Workbench. Several Web based tools were developed: MAS ${ }^{1}$, SMT-Advisor ${ }^{2}$, and C) Ducade ${ }^{3}$. Collaboration: chat, calendar and forums were used to foster collaboration; and the MSN Messenger ${ }^{\mathrm{TM}}$ provided instant messaging, a pplications sh aring, a udio / v ideo and whiteboard. Coordination: the stand alone application of MS Project was used. Information Management: based on MSN group's technology (files uploads, pictures publishing and customized html frames) was used as a repository of data/information.

CONNECT: No connections to ERP or SMEs systems were required in this prototype. Exchange information was achieved through file sharing and uploading in the environment.

MONITOR: A simple set of performance indicators were defined because the embedded coordination system was not able to track and control the development process. Indicators as milestones and dates were managed, but on-line tracking was not possible.

Step IV) The execution of the activities using the e-Engineering collaboration environment was carried out to demonstrate the development of a mechatronic product (Figure 2).

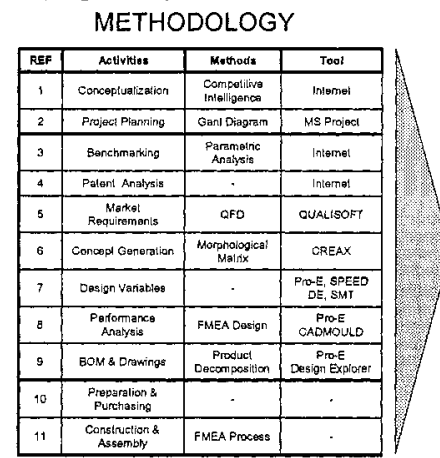



Figure 2 - Freeware collaborative tools used for a High Tech Product development pilot project

${ }^{1}$ http://cybercut.berkeley_edu/mas2/

2 http//csim.mty.itesm.mx/grupos/snt

${ }^{3} \mathrm{http} / /$ spidernan.me.berkeley.edu/ducade/ 


\section{CASE STUDY: COLLABORATIVE ENVIRONMENT FOR DRY-FREIGHT VAN DEVELOPMENT}

A collaborative e-Engineering environment was design and implemented to support a Mexican company in developing new product. The collaboration was carried out between engineers in two different cities in Mexico (Monterrey and Cordova)

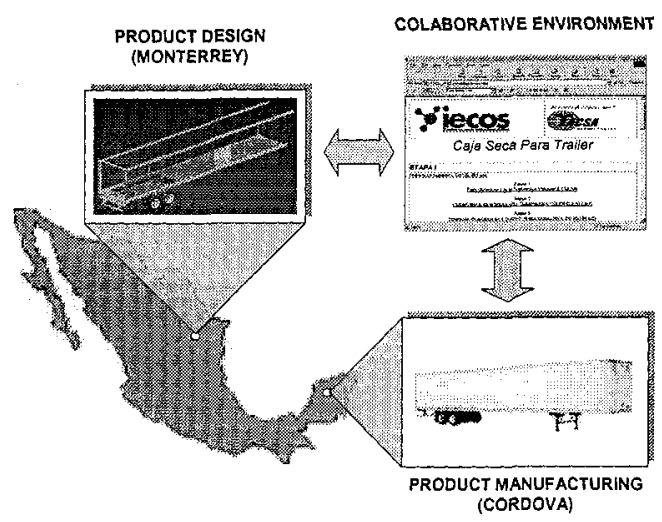

Figure 3 - e-Engineering collaboration for dry-freight van development

The objective of the project was to design and fabricate a Dry-Freight Van in a period of five months. Therefore, two processes were defined: Product Development (Dry-Freight Van) and Manufacturing Process Development. The concept of the collaboration was that the company located in Monterrey was in charge of the DryFreight design and the company in Cordova was responsible for the manufacturing process and fabrication (Figure 3 ).

Step I) Two processes were defined to set up the e-Engineering Collaborative Environment: Product Development and Manufacturing Process Development.

Step II) To design and fabricate a Dry-Freight Van it is necessary to develop a new process that allowed engineers from Monterrey to carry out concurrent activities with the engineers in Cordova, while sharing information and knowledge regarding the manufacturing capabilities and capacities of the company in Cordova. A project coordinator was defined, and leaders were assigned for both teams. The set of standard formats and reports were elaborated to allow an efficient exchange of information among teams; this was very important because even when both companies used the same CAD tool, but versions were different.

Based on the experience with the pilot project, the same freeware technologies were considered in the integration of applications to configure the collaborative eEngineering environment (Step III). However some special considerations were essential because it was an industrial development. First of all, due to information confidentiality, a dedicated server was assigned to manage the collaborative environment, therefore any information exchange would be sent through a secure 
server. Even so, the communication between companies was performed using NetMeeting ${ }^{\mathrm{TM}}$. The environment was designed with following considerations:

MODEL: In this project, it was necessary to create shared spaces. A simple Password Accessing Webpage was created, with a structure that emulated a workflow management system, according to the development process defined for the Dry-Freight Van design.

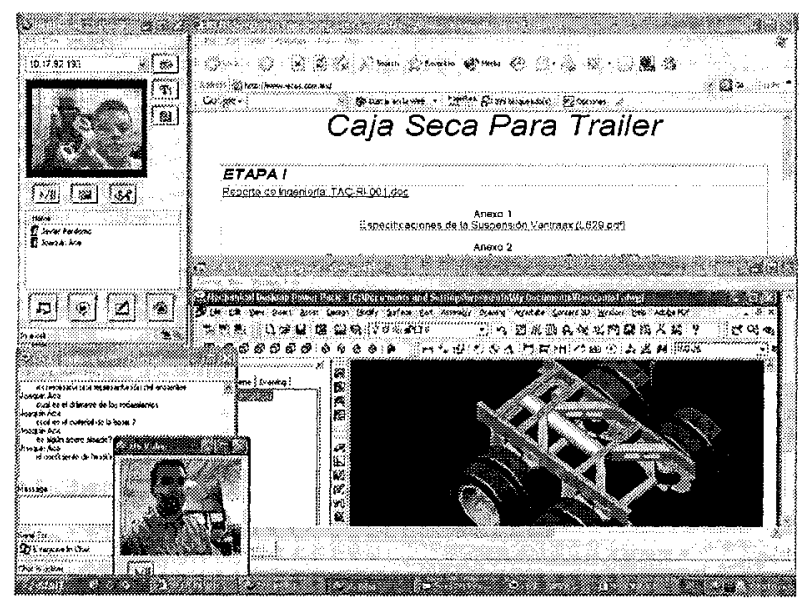

Figure 4 Interactions using the e-Engineering Collaborative Environment

INTEGRATE: Functional: stand-alone applications were used such as Mechanical Desktop, AutoCAD and Spreadsheets. The information was exchanged in AutoCAD format. Collaboration: NetMeeting ${ }^{\mathrm{TM}}$ was used because its communication capabilities were more than enough (instant messaging, applications sharing, audio / video and whiteboard). Coordination: MS P roject was e mployed to manage the project. Information Management: webpage using XTML were created mainly to store and exchange information between the engineers (with restricted access to partners involved see figure 4).

CONNECT: No external applications were required.

MONITOR: timeframes and specific product deliverables were key performance indicators used to monitor the process. The control of the process was managed using MS Project software by updating project information in the shared webpage.

The execution of the Dry-Freight Van design (Step IV) was carried out according to the schedule planned in the project. Nevertheless the fabrication of the Dry-Freight Van was not possible due to financial problems with the company in Cordova.

\section{CONCLUSION}

Typical problems in product development scenarios at different geographical locations are: the absence of a structured product development process, lack of collaboration during early stages of life cycle product realization and miscommunication between design and manufacturing engineers. This research explored how a structured methodology can be used to design and configure 
collaborative engineering environments to suits the requirements of company focusing on specific issues such as: actual development process, available knowledge; human resources capabilities, and technological constraints. A pilot project and an industrial case study were presented to demonstrate how the methodology has been used to create such collaborative environments. The execution of the engineering activities using the e-Engineering collaboration environment enable the following: (1) improve the collaboration activities among engineers based on a structured development process (2) facilitate the coordination and exchange of information using the shared spaces (3) make it possible the interactions of teams located at different geographic locations and (4) improve the engineering tasks by using a set of functional tools. However further research in relation of how the collaborative activities are performed are needed because a collaborative engineering environment supported only by information technology is not sufficient to improve global product development. There is a need to understand better of how coordination, collaboration and cultural issues restraint engineers from a company to achieve a successful e-Engineering practice.

\section{ACKNOWLEDGMENTS}

The authors acknowledges the Chair in Mechatronics from the Instituto Tecnológico y de Estudios Superiores de Monterrey (ITESM - Campus Monterrey) for the support in the development of this research.

\section{REFERENCES}

1. Aca J., Mejía R.,Velandia M., García E., Galeano N., Ahuett H., Molina A., Wright P., "Integrated Product Development in Virtual Enterprises Supported by Web-based Applications", in Process and Foundations for Virtual Organizations, L.M. Camarinha-Matos, H. Afsarmanesh (Eds.), Kluwer Academic Publishers, 2003, pp. 361-368.

2. Bochenek, G.M.; Ragusa, J.M.; "Virtual collaborative design environments: a review, issues, some research, and the future". International Conference on Management of Engineering and Technology. PICMET '01. Portland, 2001

3. Lee, R. S., T saib, J. P., K aoc, Lind, C. I. and Fane, K. C., 2003, "STEP-based product modeling system for remote collaborative reverse engineering", Robotics and Computer-Integrated Manufacturing, Volume 19, Issue 6, Pages 543-553.

4. Mervyn, F., Senthil Kumar, A., Bok, S. and Nee, A. Y. C, 2003, "Developing distributed applications for integrated product and process design", Computer Aided Design, Article in Press.

5. OUSD, 1998, "DoD Integrated Product and Process Development Handbook", Office of the Under Secretary of Defense (OUSD), Washington, DC - 20301-3000, August 1998.

6. Song, P., Tang, M. and Dong J. 2001, "Collaborative model for concurrent product design", IEEE Sixth International Conference on Computer Supported Cooperative Work in Design, 12-14 July 2001, Pages 212-217.

7. Swink, M., Sandving, J.C. and Mabert, V., 1996, "Customizing Concurrent Engineering Processes: Five Case Studies", Journal of Production and Innovation Management, Volume 13, Pages 229 244

8. Tipnis V.A., "Evolving Issues in Product Life Cycle Design: Design for Sustainability", Chapter 13, in Handbook of Life Cycle Engineering: Concepts, models and technologies, Edited by A. Molina, A. Kusiak and J. Sanchez, London, Kluwer Academic Publishers, pp. 399-412. 1999.

9. Yan, P. and Zhou, M, 2003, "A life cycle engineering approach to development of flexible manufacturing systems", IEEE Transactions on Robotics and A utomation, V olume 19, Issue 3 , June 2003, Pages 465-473. 